\title{
Research on Utilization of Tactile Tiles and Behavior of Visually Impaired Persons on Railway Platforms
}

\author{
Naoki MIZUKAMI \\ Assistant Senior Researcher, \\ Psychology \& Physiology, Human Science Div. \\ Kohei FUJINAMI \\ Assistant Senior Researcher,

\begin{abstract}
Hisato OHNO
Assistant Senior Researcher, Ergonomics, Human Science Div.
\end{abstract} \\ In order to improve guiding systems like tactile tiles for the visually impaired on the \\ railway platform, we need to know how tactile tiles are used and how these people behave \\ on railway platforms at present. But there are few reports on this theme. In this study, 67 \\ visually impaired persons who use railways alone were interviewed. This research re- \\ vealed that (1) dot type tactile tiles are used by $84 \%$ as a guide to follow when they walk \\ parallel to the rail, although the main purpose of those tiles are to give warning of the \\ platform edge; (2) 76\% utilize bar type tactile tiles crossing dot type tactile tiles at a right \\ angle at the platform edge as a cue to detect stairs; and (3) 70\% walk along dot type tactile \\ tiles on island platforms. The percentage of the people who walk along dot type tactile tiles \\ is equal to that of those who walk along the wall side of the platforms, $33 \%$ each on \\ opposite platforms.
}

Keywords : visually impaired person, tactile tiles for the visually impaired, railway platform

\section{Introduction}

To support the social participation of the aged and the disabled, promoting easily accessible public traffic facilities like railways is indispensable. For these people, a variety of measures are taken in Japanese railways ${ }^{1)}$. But visually impaired persons who use railways alone are confronted with a number of difficulties ${ }^{2)}{ }^{3)}$. One is moving on railway platforms. Visually impaired persons need tactile tiles for guiding the visually impaired (hereafter referred to as "tactile tiles") on railway platforms ${ }^{2) 3}$. Tactile tiles are diligently set according to a guideline1). But there are no sufficient details to indicate the way to arrange tactile tiles on the platform. A safety improvement is required by standardizing the rules for the layout of tactile tiles on the platform.

In order to improve guiding systems like tactile tiles on the railway platform, we need not only analyze the cases of falling accidents from the platforms ${ }^{2) 3}$ and the current situation of laid tactile tiles, but also know how these people behave on the platforms at present. But there are few reports on this theme. In this study, 67 visually impaired persons who used railways alone were interviewed.

\section{Historical background and meanings of tactile tiles}

At first, before getting into the main subject, we will mention the historical background and the meanings of tactile tiles. Tactile tiles with raised parts for guiding the people with vision impairment were developed in Japan and installed first in 1967. Tactile tiles are now widespread throughout Japan. As the effectiveness of these guiding systems based on the Japanese version is recognized, a variety of countries are adopting these guiding systems as a domestic standard ${ }^{4) 5)}$. In Japan, tactile tiles were standardized by Japanese Industrial Standard (JIS) in $2001^{6) 7}$. In parallel, those patterns are so diversified that they are required to be standardized internationally. International Organization for Standardization (ISO) is discussing an international standard at present ${ }^{8)}$.

It was in the 1970 s that tactile tiles started to be installed at railway stations in Japan. Tactile tiles are now placed at almost all railway platforms in metropolitan areas.

The tactile tiles installed at railway platforms are divided broadly into two types. One is the bar type tactile tile having bar shaped bumps which gives directional information to visually impaired persons by means of the parallel direction of the bar bump. The guidance to some direction on the level is achieved by setting these tactile tiles in continuum. On platforms, for example, this type of tactile tile is placed to indicate a stair from the area close to the platform edge.

The other is the dot type tactile tile which has dot shaped bumps giving warning or calling attention to pedestrians who have impaired vision through contact by foot or white cane. This type of tactile tile is used to show the difference in the height of level surface, both at the top and bottom of stairs (just before the stair), and in conjunction with bar type tactile tiles at an angle or the junction of paths for blind persons. On railway platforms, for example, tactile tiles of a width of $300 \mathrm{~mm}$ or $400 \mathrm{~mm}$ are placed $800 \mathrm{~mm}$ back (as a rule) from platform edges parallel to the rail. 


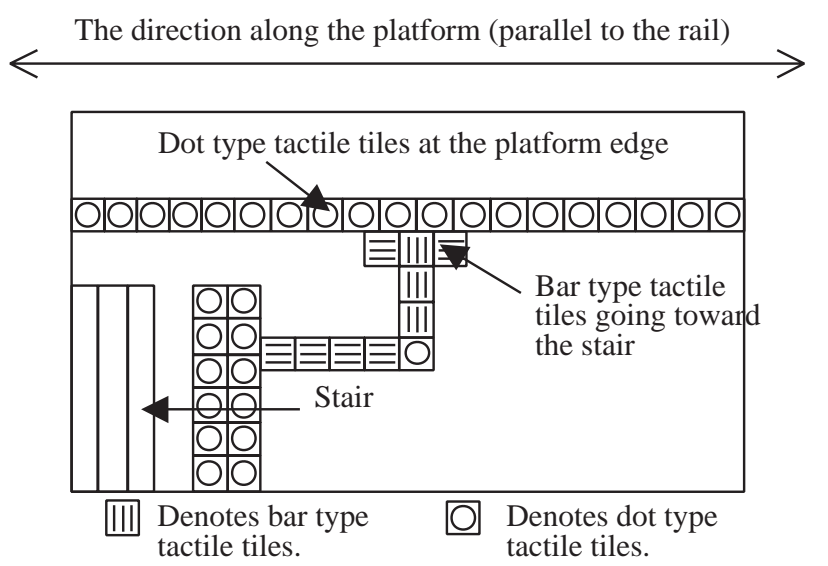

Fig. 1 Layout example of tactile tiles at railway platform

\section{Method}

\subsection{Locations and method of interviews}

We interviewed visually impaired persons individually for an hour and a half per person at related establishments in Tokyo and Osaka.

\subsection{Characteristics of interviewees}

We collected the interviewees through a public advertisement in the 'Tenji Mainichi' (Mainichi News Paper Co, Ltd.) and by the recommendation of related organizations for visually impaired persons. The subjects were blind people who use railways by themselves, with a white cane used in their daily life. As a result, 67 visually impaired persons participated in this interview (24 persons in Tokyo, and 43 persons in Osaka).

The following characteristics of the interviewees were given by a verbal self-report. Therefore, the age at which their present eyesight began and when they started to walk alone with a white cane may include errors of several years.

\section{(1) Age and Sex}

The average age was 44.2. The interviewees were 51 males and 16 females, four in their $20 \mathrm{~s}, 23$ in their $30 \mathrm{~s}$, 14 in their $40 \mathrm{~s}, 22$ in their $50 \mathrm{~s}$, three in their $60 \mathrm{~s}$, and one in their $70 \mathrm{~s}$.

(2) Eyesight

The visual status is as follows hereinafter, in terms of the number of interviewees: blindness-40, possible to recognize light and shade-23, possible to recognize movement of hands before the eyes-1, possible to recognize the number of fingers before the eyes-1, partial sight (low vision)-1

(3) Age at which their present eyesight began

The age at which their present eyesight began is as follows; 0 year-15, P to 9 years-10, 10 to 19 years-19, 20 to 29 years-10, 30 to 39 years-3, 40 to 49 years- 6,50 to 59 years- $\mathrm{S}$

(4) Years of experience in walking alone with a white cane

The experience of walking alone with a white cane is as follows: under 10 years-8, 10 to 20 years-15, 20 to 30 years-20, 30 to 40 years-17, 40 to 50 years- 6,50 to 60 years-1

(5) Frequency of using trains

The frequency of using trains is as follows: more than four times a week-47, one to three times a week-19, less than once a week-1

\section{Results}

\subsection{Whether or not they attempted to distinguish between the two types of tactile tiles}

All interviewees knew the existence of the dot type tactile tiles and bar type tactile tiles. And 63 of 67 persons answered the right meaning of each tactile tile.

We asked visually impaired persons whether or not they thought that they could correctly recognize the dot type tactile tiles and bar type tactile tiles, respectively, when they attempted to distinguish them. We also asked if they actually attempted to distinguish between the two types of tactile tiles on the railway platform. The results are shown in Tables 1 and 2 .

\section{Table 1 Possible or not possible to distinguish between two types of tactile tiles}

\begin{tabular}{|c|c|c|c|c|}
\hline & $\begin{array}{c}\text { Always } \\
\text { possible } \\
\text { to know } \\
\text { difference }\end{array}$ & $\begin{array}{c}\text { Mostly } \\
\text { possible } \\
\text { to know } \\
\text { difference }\end{array}$ & $\begin{array}{c}\text { Not } \\
\text { possible } \\
\text { to know } \\
\text { difference } \\
\text { very well }\end{array}$ & Others \\
\hline $\begin{array}{c}\text { Number of } \\
\text { persons }\end{array}$ & 40 & 16 & 7 & 4 \\
$\begin{array}{c}\text { Number } \\
\text { within } \\
\text { ( ) is \% }\end{array}$ & $(59.7)$ & $(23.9)$ & $(10.4)$ & $(6.0)$ \\
\hline
\end{tabular}

Table 2 Use two types of tactile tiles to distinguish on platform

\begin{tabular}{|c|c|c|c|c|}
\hline & $\begin{array}{c}\text { Always } \\
\text { use them } \\
\text { to distin- } \\
\text { guish }\end{array}$ & $\begin{array}{c}\text { Sometimes } \\
\text { use them } \\
\text { to distin- } \\
\text { guish }\end{array}$ & $\begin{array}{c}\text { Not use } \\
\text { them to } \\
\text { distin- } \\
\text { guish }\end{array}$ & Others \\
\hline $\begin{array}{c}\text { Number of } \\
\text { persons }\end{array}$ & 12 & 23 & 28 & 4 \\
$\begin{array}{c}\text { Number } \\
\text { within }\end{array}$ & $(17.9)$ & $(34.3)$ & $(41.8)$ & $(6.0)$ \\
$($ ) is $\%$
\end{tabular}

More than $80 \%$ of the interviewees think that they can distinguish between dot type tactile tiles and bar type tactile tiles when they attempt to do so. In comparison, there are many persons who are not used to distinguishing between the tactile tiles on the platform. The reason is that it is difficult to concentrate on the difference of the tactile tiles because there is a number of other important information elements on the platform and it is not important to distinguish between the difference of the tactile tiles, but those existence is important on the platform. 


\subsection{Use of tactile tiles on platform}

\subsubsection{Use of tactile tiles at platform edge}

All interviewees knew that tactile tiles were set in the direction of the rail at the platform edge. 62 persons $(92.5 \%)$ knew the tactile tiles were dot type one. There are 65 persons $(97.0 \%)$ who utilize these tactile tiles at the platform edge for several purposes. We gave them five different choices (multiple choices are permitted), (1) as a warning of the platform edge, (2) as a guide to follow when they walk parallel to the rail, (3) as an indication of the distance to the train car door, (4) to confirm the existence of the tiles when getting off a train and going toward the middle of the platform, and (5) others.

Table 3 shows the number of persons who use the bar type tactile tiles for each purpose, and their percentage to the 67 persons.

The results showed dot type tactile tiles at the platform edge have various usages. It is notable that they are not only as a warning of the platform edge but also as a guide to follow when walking along the platform.

Table 3 Use of dot type tactile tiles on platform*

\begin{tabular}{|c|c|c|c|c|c|}
\hline & $\begin{array}{c}\text { Warning } \\
\text { to } \\
\text { edge }\end{array}$ & $\begin{array}{c}\text { Guide } \\
\text { for } \\
\text { moving }\end{array}$ & $\begin{array}{c}\text { Indi- } \\
\text { cating } \\
\text { distance } \\
\text { to door }\end{array}$ & $\begin{array}{c}\text { Confirming } \\
\text { tiles when } \\
\text { going } \\
\text { inside of } \\
\text { platform }\end{array}$ & Others \\
\hline $\begin{array}{c}\text { Number } \\
\text { of } \\
\text { persons }\end{array}$ & 62 & 56 & 33 & 27 & 0 \\
$\begin{array}{c}\text { Number } \\
\text { within } \\
\text { ( ) } \\
\text { is \% }\end{array}$ & $\begin{array}{c}(92.5) \\
(83.6)\end{array}$ & $(49.3)$ & $(40.3)$ & $(0.0)$ \\
\hline
\end{tabular}

${ }^{\star}$ Multiple choices are permitted.

\subsubsection{Tactile tiles around stairs on platform}

Out of 67 persons, 66 persons knew that there were dot type tactile tiles before stairs on the platform.

Fifty-eight persons (86.6\%) knew bar type tactile tiles were laid from the platform edge to the stair. Fifty-two persons $(77.6 \%)$ utilized these tiles for some purpose.

The way we made them choose the purpose of using the tiles were as follows: (1) as a cue to detect stairs when walking at the platform edge parallel to the rail (at the platform edge $\Rightarrow$ stair),(2) to know the proximity of the stairs (at the middle of platform $\Rightarrow$ stair), (3) as a guide

Table 4 Use of bar type tactile tiles connects platform edge to stairs*

\begin{tabular}{|c|c|c|c|c|}
\hline & $\begin{array}{c}\text { At } \\
\text { platform } \\
\text { edge } \Rightarrow \\
\text { stair }\end{array}$ & $\begin{array}{c}\text { At the } \\
\text { middle of } \\
\text { platform } \\
\Rightarrow \text { stair }\end{array}$ & $\begin{array}{c}\text { Stair } \Rightarrow \\
\text { platform } \\
\text { edge }\end{array}$ & Others \\
\hline $\begin{array}{c}\text { Number } \\
\text { of } \\
\text { persons }\end{array}$ & $\begin{array}{c}51 \\
\text { Number } \\
\text { within } \\
(76.0)\end{array}$ & $\begin{array}{c}32 \\
(42.7)\end{array}$ & $\begin{array}{c}24 \\
(35.8)\end{array}$ & $\begin{array}{c}(4.5) \\
\text { is } \%\end{array}$ \\
\hline
\end{tabular}

${ }^{\star}$ Multiple choices are permitted when they approach the platform edge from the stair (stair $\Rightarrow$ platform edge), and (4) others.

Table 4 shows the number of persons who use the bar type tactile tiles for each purpose, and their ratio to the 67 persons.

Of the interviewees, $76 \%$ utilize bar type tactile tiles crossing dot type tactile tiles at a right angle as a cue to detect stairs. We asked $58 \%$ of interviewees who knew such arrangement of bar type tactile tiles whether or not they needed these tactile tiles. Out of the persons who knew such arrangement of tactile tiles, $80 \%$ needed them.

\subsection{Moving along the platform}

\subsubsection{Line of movement on the platform}

We surveyed the position on the island platforms and opposite platforms where they move along the platform, respectively. The two forms of platforms are shown in Fig. 2 and Fig. $3^{3)}$. The results are shown in Table 5 .

On island platforms, $70 \%$ walk along dot type tactile tiles. On opposite platforms, the percentage (33\%) of the persons who walk along dot type tactile tiles is equal to that of those who walk along the wall side of the platforms.

On island platforms, the result indicates that they cannot help using the dot type tactile tiles as a guide to

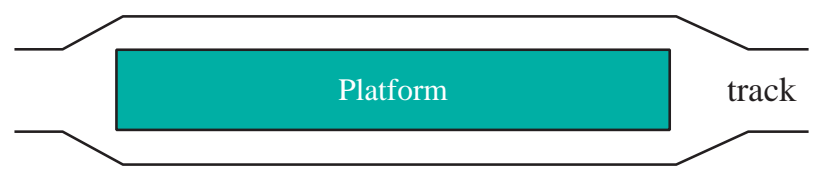

Fig. 2 Island platform

\section{Platform}

track

\section{Platform}

Fig. 3 Opposite platforms

Table 5 The walking positions when moving along platform*

\begin{tabular}{|c|c|c|c|c|c|c|}
\hline & $\begin{array}{c}\text { Area } \\
\text { close } \\
\text { to } \\
\text { plat- } \\
\text { form } \\
\text { edge }\end{array}$ & $\begin{array}{c}\text { In- } \\
\text { side } \\
\text { of } \\
\text { plat } \\
\text { form }\end{array}$ & $\begin{array}{c}\text { Along } \\
\text { the } \\
\text { wall }\end{array}$ & $\begin{array}{c}\text { As the } \\
\text { case may } \\
\text { be }\end{array}$ & $\begin{array}{c}\text { Unde- } \\
\text { cided }\end{array}$ & Others \\
\hline $\begin{array}{c}\text { Oppo- } \\
\text { site } \\
\text { plat- } \\
\text { form }\end{array}$ & $\begin{array}{c}22 \\
(32.8)\end{array}$ & $\begin{array}{c}10 \\
(14.9)\end{array}$ & $\begin{array}{c}22 \\
(32.8)\end{array}$ & $\begin{array}{c}(13.4) \\
(0.0)\end{array}$ & $\begin{array}{c}4 \\
(6.0)\end{array}$ \\
\hline $\begin{array}{c}\text { Island } \\
\text { plat- } \\
\text { form }\end{array}$ & $\begin{array}{c}47 \\
(70.1)\end{array}$ & $\begin{array}{c}9 \\
(13.4)\end{array}$ & - & $\begin{array}{c}8 \\
(11.9)\end{array}$ & $\begin{array}{c}(0.0) \\
(4.5)\end{array}$ \\
\hline
\end{tabular}

*The figure is the number of persons out of 67 persons. The number within () is \%. 
follow at the platform edge, although the tactile tiles are placed at the area close to the hazardous platform edge. In this connection, the main reason is the difficulty to walk along the wall side because there are vending machines, benches, trash boxes etc., although they want to walk along the wall.

\subsubsection{Foot position and use of white cane when walking} along platform

Since 60 persons walked along dot type tactile tiles at the platform edge, we asked them the relationship between the tactile tiles and their foot positions, as well as the way they use their white cane. Concerning their foot positioning, we let them choose (1) walking with only one foot on the tactile tiles, (2) walking on the top of the tactile tile with both feet, (3) walking with both feet off the tactile tiles, (4) undecided, and (5) others.

Next questions were as follows. In the case of (1), at which position is the foot off the tactile tiles, inside or outside the tactile tiles? In the case of (3), at which position are both feet, inside or outside the tactile tiles?

Concerning the method of using the white cane, in the case of 42 persons putting only one foot on the tactile tiles (See table 6), there are two main ways, sliding technique, and touch-tapping. The interviewees who used these two techniques in our study were 21 and 7 persons out of 42 persons, respectively. In the case of the 12 persons having both feet off the tactile tiles, 11 persons used the white cane with the slide technique.

Table 6 The foot position in walking along the platform*

\begin{tabular}{|c|c|c|c|c|c|c|}
\hline & \multicolumn{2}{|c|}{$\begin{array}{c}\text { Only one } \\
\text { foot } \\
\text { putting } \\
\text { on tiles }\end{array}$} & \multicolumn{2}{|c|}{$\begin{array}{l}\text { Both feet } \\
\text { not } \\
\text { putting on } \\
\text { tiles }\end{array}$} & $\begin{array}{c}\text { Both } \\
\text { feet } \\
\text { putting } \\
\text { on tiles }\end{array}$ & $\begin{array}{l}\text { Unde- } \\
\text { cided } \\
\text { and } \\
\text { others }\end{array}$ \\
\hline $\begin{array}{c}\text { Foot } \\
\text { position }\end{array}$ & \multicolumn{2}{|c|}{$\begin{array}{c}42 \\
(70.0)\end{array}$} & \multicolumn{2}{|c|}{$\begin{array}{c}12 \\
(20.0) \\
\end{array}$} & $\begin{array}{c}4 \\
(6.7)\end{array}$ & $\begin{array}{c}2 \\
(3.3)\end{array}$ \\
\hline \multirow{2}{*}{$\begin{array}{l}\text { Foot or } \\
\text { feet put } \\
\text { inside or } \\
\text { outside } \\
\text { tiles }\end{array}$} & In & Out & In & Out & \multirow[b]{2}{*}{-} & \multirow[b]{2}{*}{-} \\
\hline & 37 & 5 & 11 & 1 & & \\
\hline
\end{tabular}

*The figure is the number of persons out of 67 persons.

The number within () is \%.

\subsection{Falling from a platform}

There are three necessary conditions for visually impaired persons to move on a railway platform safely9). One is to acquire a proper walking technique including the way of using a white cane, the second is arranging the physical environment for moving with ease (for example safety fences) and the third is support by people assisting visually impaired persons. To arrange tactile tiles on platforms is one of the second point. Generally speaking, tactile tiles are the minimum requirements for visually impaired persons to move on a platform and they have limits for preventing accidents such as falling from a platform ${ }^{3}$. However it seems they don't quite contribute to the prevention of falling accidents.
In case of assumption the effectiveness of tactile tiles by comparing whether or not tactile tiles are laid or not when the accident occurred, there are some things we need to know. They are the frequency, and the duration of experience walking on the platform under the condition of non-presence of tactile tiles (and presence of tactile tiles). It is pretty difficult for us to know in detail and we don't have enough data concerning the previously mentioned matters in our study. Although, therefore, our result was not absolute, we examined the relationship between the number of falling accidents and the presence or non-presence of tactile tiles.

In this survey, 38 of 67 (56.7\%) persons had experienced falling from a platform. The total cases of the accidents were 99 in number. In 49 of 99 where persons had fallen from the platform, they were able to recall whether or not tactile tiles were laid. These 49 cases were classified into two groups. They are as follows. Tactile tiles were not present at the incidence of falling from the platform in one group, whereas they were present in the other group. In 36 cases, tactile tiles were not laid at the place, and in 13 cases, tactile tiles were laid. Some interviewees who had fallen more than once from a platform edge mentioned that they had stopped falling after tactile tiles were placed on the platform edge. These numbers and comments may imply the effectiveness of tactile tiles to prevent falling from a platform, although we can't exclude some possibilities influencing this, such as, the factor that the persons had become more careful after experiencing a falling accident.

\section{Conclusions}

In our study, we found the following.

1) Dot type tactile tiles are used by $84 \%$ of the interviewees as a guide to follow when they walk along the platform, although they are originally a warning of the platform edge.

2) In this survey, $76 \%$ utilize bar type tactile tiles crossing dot type tactile tiles at a right angle at the platform edge as a cue to detect stairs.

3) On island platforms, $70 \%$ walk along dot type tactile tiles. On opposite platforms, the percentage (33\%) of the persons who walk along dot type tactile tiles is equal to that of those who walk along the wall side of the platforms.

4) When walking along dot type tactile tiles along platform edge, $70 \%$ (42 of 60 persons) move with one foot putting on tactile tiles. The number of the persons using a white cane with slide technique is 21 of the persons who walk along the tactile tiles on the platform.

We are now trying to develop a new type of tactile tile on the platform ${ }^{10)}$ and to standardize the rules for their layout. It is required to improve the guiding system like tactile tiles in consideration of the actual situations verified through the above-mentioned interviews. 


\section{Acknowledgment}

This study was assisted by a government subsidy. We express our gratitude to those who cooperated with the interview and this study.

\section{References}

1) Foundation for Promoting Mobility and Ecological Transportation: "The guideline of the promoting easily accessible public transportation infrastructure (in Japanese)," 2001.

2) Okura, M., Murakami, T., Shimizu, M. and Tauchi, M.: "The relationship between some characteristics of orientation and mobility of visually impaired travelers and falls from train platforms (in Japanese)," Jpn.J.of Ergonomics 31,1, pp.1-8, 1995.

3) Akatsuka, H., Kusukami, K. and Sato, Y.: "Psychological analysis on visually impaired persons' Falling from railway platform," QR of RTRI Vol.40, No.4, 1999.

4) Australian Standard: Design for access mobility, part 4; "Tactile ground surface indicators for the orientation of people with vision impairment," AS 1428.4$1992,1992$.
5) U.S. Department of Transportation: "Detectable warning surface: Color, Contrast and Reflectance," FTA-MA-06-0201-94-3-1994.

6) Ministry of International Trade and Industry National Institute for Technology and Evaluation: "Reports of fundamental research on standardization relating to tactile tiles for guiding the visually impaired, aiming at standardization of patterns (study of the relationship between individual pattern and ease of recognition)," 1998.

7) Japanese Industrial Standard (JIS): "Dimensions and patterns of raised parts of tactile ground surface indicators for blind persons (JIIS T 9251)," 2001.

8) ISO: "Technical aids for blind and vision impaired persons - Tactile ground/floor surface indicators", ISO/ CD 11520.2(E), International Organization for Standardization, 1997.

9) Okura, M., Murakami, T., Shimizu, M. and Tauchi, M.: "A Consideration for Improving Visually Impaired Traveler's Safety", Health Science (in Japanese), Vol. 11, No.3 pp148-152, 1995.

10) Ohno, H., Suzuki, H., Fujinami, K., Mizukami, N., Shinomiya, A., Sueda, O. and Tauchi, M.: "A new tactile indicator specifying the inside of a railway platform," The 10th International Conference on Environmental Ergonomics, 2002. 